\title{
Aspectos éticos de los bancos de datos de DNA de interés policial* $^{*}$
}

\author{
Ethical aspects of DNA databanks of police interest
}

\author{
Francesc Mestres ${ }^{1}$ (iD), Cinta Pegueroles QueralT ${ }^{2}$ (iD) Josep Vives-Rego ${ }^{3}$
}

\begin{abstract}
RESUMEN: El primer banco de datos policial basado en perfiles genéticos de DNA se introdujo en el Reino Unido en 1995. La identificación de posibles sospechosos se realiza por la comparación directa de un perfil genético recuperado del lugar de los hechos con otro almacenado en un banco de datos. Desde un principio se ha demostrado que dichos bancos de DNA son una herramienta de investigación policial poderosa, pero que presenta diversos problemas éticos. Posteriormente se fue más allá buscando coincidencias parciales, que podrían indicar un vínculo familiar entre un perfil genético almacenado y otro obtenido en el lugar de los hechos. Este procedimiento genera un elevado número de sospechosos potenciales entre personas ajenas al caso que se investiga. Recientemente la búsqueda policial basada en el DNA ha penetrado en bancos de datos de interés no criminal, sino destinados a estimar el origen étnico de personas o descubrir familiares lejanos. Este tipo de búsquedas ha suscitado la posibilidad de generar un banco de datos universal de DNA, donde toda la población estuviese incluida. Estos y otros aspectos bioéticos respecto a la información basada en el DNA y a su acceso son tratados en el presente artículo.
\end{abstract}

Palabras clave: DNA, perfil genético, bioética, banco de datos policial, búsqueda familiar, búsqueda familiar de largo alcance, dragnet, banco de datos universal de DNA.

\begin{abstract}
The first police databank based on DNA genetic profiles was introduced in the UK in 1995. Identification of potential suspects is carried out by direct comparison of a genetic profile retrieved from the crime scene with another stored in a databank. DNA databanks have been proven from the outset to be a powerful police investigative tool, but they present a number of ethical issues. Later, it went further looking for partial coincidences, which could indicate a family link between a stored genetic profile and one obtained at the crime scene. This procedure generates a high number of potential suspects among people not related with the case under investigation. Recently, the DNA-based police search has penetrated databanks of non-criminal interest, but aimed at estimating the ethnic origin of people or discovering distant relatives. This type of search has raised the possibility of generating a universal DNA databank, where the entire population were included. These and other bioethical aspects regarding information based on DNA and its access are dealt with in this article.
\end{abstract}

Keywords: DNA, genetic profile, bioethics, police databank, familial search, long-range familial search, dragnet, universal DNA databank.

SUMARIO: I. INTRODUCCión. 1. Preámbulo filosófico. 2. Origen y utilización de los bancos de datos de DNA de interés policial. II. DESCRIPCIÓN DE LOS DISTINTOS TIPOS DE BANCOS DE DATOS BASADOS EN EL DNA. III. PERMANENCIA DE LA INFORMACIÓN EN LOS BANCOS DE DATOS. IV. LAS BÚSQUEDAS FAMILIARES. V. LAS BÚSQUEDAS FAMILIARES DE LARGO ALCANCE. VI. LOS DRAGNETS O 'PESCA DE ARRASTRE'. VII. BANCOS DE DATOS DE DNA UNIVERSALES. VIII. CONCLUSIONES Y PERSPECTIVAS DE FUTURO. IX. BIBLIOGRAFÍA.

\footnotetext{
* Fecha de recepción: 05/03/2021 - Fecha de aceptación: 03/11/2021. Cita recomendada: Mestres, F., Pegueroles Queralt, C., \& Vives-Rego, J. (2021). Aspectos éticos de los bancos de datos de DNA de interés policial, Bioderecho.es, (13), 1-15. https://doi.org/10.6018/bioderecho.471891

${ }^{1}$ Catedrático, Universitat de Barcelona. Correo: fmestres@ub.edu

${ }^{2}$ Profesora Asociada, Universitat de Barcelona. Correo: cpegueroles@ub.edu

${ }^{3}$ Profesor Honorífico, Universitat de Barcelona. Correo: temivives@telefonica.net
} 


\section{INTRODUCCIÓN}

\section{Preámbulo filosófico}

El utilitarismo como filosofía moral y política desde Bentham y Mill hasta nuestros días se fundamenta en la célebre expresión: "la mayor felicidad del mayor número". Sin embargo, los constantes retos sociales que surgen de los avances de la ciencia y la tecnología hacen obligatorio su constante refinamiento, remodelación y reformulación en los contextos en que los intereses económicos particulares de los grupos de presión tienden a predominar sobre los intereses del ciudadano común que constituyen la mayoría. Hoy sabemos que el conocimiento y el aprendizaje no son elementos que nos lleguen ni beneficien pasivamente. Son el fruto de nuestra interacción con la sociedad que afecta positiva o negativamente a todos los individuos. Es por ello, que en la utilización de los bancos de datos policiales debe regir la ética moderna. Es incuestionable que un objetivo sociopolítico primordial en nuestros tiempos es conseguir el máximo beneficio para el mayor número de personas (principio utilitarista). Sin embargo, esa máxima en el mundo actual debe resolver como ser aplicada cuando las desigualdades sociales no cesan de aumentar. Es decir, ¿es éticamente admisible proporcionar el mismo beneficio a todos los sectores sociales más allá de sus necesidades y su precariedad para resolverlas? La extrapolación de esta pregunta a los beneficios que indudablemente aportan los bancos de datos policiales en general se puede formular del siguiente modo: ¿todos los sectores sociales están igualmente necesitados de los beneficios de la utilización de los bancos de datos policiales? Cuando hay errores o se conculcan los derechos (a la privacidad, por ejemplo) itodos los sectores sociales salen igualmente perjudicados o beneficiados? ¿Qué procedimientos científicos y jurídicos deben implementarse para que los más necesitados no sufran más daños o reciban menos beneficios de la utilización de los bancos policiales? Responder a estas preguntas constituye una tarea hercúlea que ultrapasa el propósito de este trabajo. Sin embargo, aspiramos a desbrozar el camino hacia su resolución.

\section{Origen y utilización de los bancos de datos de DNA de interés policial}

El origen de la Genética forense (definida como la utilización de los conocimientos de la Genética en la administración de la Justicia), se remonta al año 1900 cuando Landsteiner describió el grupo sanguíneo $\mathrm{ABO}^{1}$. Sin embargo, el auge actual de esta especialidad tuvo lugar gracias a la utilización del DNA ${ }^{2}$ por parte de Jeffreys en los casos Sarbah (una prueba de parentesco) y Pitchfork (un caso criminal) en los años ochenta del siglo pasado ${ }^{3},{ }^{4},{ }^{5}$. Al empezar a utilizar dicha molécula y dada la inexperiencia por parte de policías, analistas de laboratorio y juristas, se cometieron una serie de errores de procedimiento, análisis e interpretación que desembocaron en la eliminación como pruebas de una serie de evidencias basadas en el DNA durante el célebre

\footnotetext{
${ }^{1}$ JOBLING, M. A., GILL, P., “Encoded evidence: DNA in forensic analysis”, Nat. Rev. Genet., vol. 5, 2004, pp. 739751.

${ }^{2}$ Aunque en lengua castellana habitualmente se usa ADN, nosotros utilizaremos DNA al ser el nombre científico de la molécula.

3 JEFFREYS, A.J., “Genetic fingerprinting”, Nature Medicine, vol. 11, 2005, pp. 1035-1039.

${ }^{4}$ MESTRES, F., VIVES-REGO, J., “Genética forense: entre la tecnociencia y la imaginación”, Ludus Vitalis, vol. 17, 2009a, pp. 447-450.

${ }^{5}$ KAYE, D. H., The double helix and the law of evidence, Harvard University Press, Cambridge (MA), USA, 2010.
} 
juicio de O. J. Simpson ${ }^{6}{ }^{7}$. Como consecuencia de este caso, diferentes administraciones norteamericanas se pusieron manos a la obra para mejorar todas las deficiencias detectadas de forma que no se volviesen a cometer los mismos errores otra vez. Este fue un gran paso adelante en el uso del DNA en la Administración de la Justicia. Con los años, las técnicas experimentales fueron mejorándose gracias al impulso pionero tanto del Forensic Science Service del Reino Unido y como del FBI. En consecuencia, se generalizó el uso de los marcadores genéticos denominados $\mathrm{STR}^{8}$ y su aceptación por parte del Derecho, especialmente el Penal. Con un conjunto suficiente de STR (entre unos 15 y 25) se podía obtener el perfil genético (o genotipo) de una persona concreta lo cual permitía su identificación de manera extremadamente precisa.

El Forensic Science Service tuvo una idea original: recopilar los perfiles genéticos de las personas arrestadas en un banco de datos policial ${ }^{9}$. Su creación se basaba en una serie de postulados derivados de la práctica policial: 1. Los delincuentes tienden a reincidir; 2. La severidad de los delitos acostumbra a incrementar con la edad del malhechor: 3 . Un número relativamente reducido de delincuentes son responsables de un gran número de delitos. Una vez establecido uno de estos bancos la policía actuaría de la siguiente forma: a partir de muestras biológicas recogidas en el lugar de los hechos (por ejemplo, sangre, saliva, cabellos, restos epiteliales, o semen) se extraería el DNA, se obtendría el perfil genético de los sospechosos y se buscaría en dicho banco de datos si se trataba de un reincidente cuya información genética ya había sido previamente introducida ${ }^{10}$. A veces se encuentra una coincidencia de perfiles (lo que en el argot se denomina un 'match') con lo que se puede sospechar razonablemente de que la persona identificada ha cometido el delito que se investiga. Otras veces no se encuentra esta coincidencia y se guarda el perfil genético obtenido en el lugar de los hechos en un fichero informático especial. Dado que el banco de datos va incorporando nuevos perfiles de personas identificadas, cada cierto tiempo se realiza una búsqueda entre los perfiles genéticos de personas introducidas en el banco de datos y los pertenecientes a los recogidos en el lugar de los hechos que quedan por identificar. Con este procedimiento es posible encontrar coincidencias ('match') e identificar a los sospechosos de delitos cometidos tiempo atrás. Es por tanto evidente que los marcadores genéticos y los bancos de datos policiales han sido, y en la actualidad son, un medio poderoso de investigación que hasta su introducción era insospechado. Es en este momento cuando debemos poner sobre la mesa un valor adicional de la forensia en general y de modo particular de la Genética Forense. La ciencia forense no solo ayuda satisfactoriamente al trabajo policial y a la Administración de Justicia, sino que también muestra a la sociedad que las instituciones tienen medios muy eficaces para imputar, arrestar, juzgar y sentenciar a los delincuentes, siendo por tanto a todos los efectos un factor disuasorio del crimen ${ }^{11}$. Podemos asegurar que el desarrollo de la forensia en todas sus vertientes ha fortalecido el poder de la

\footnotetext{
${ }^{6}$ BUTLER, J.M., Forensic DNA Typing, Elsevier Academic Press, Burlington (MA), USA, 2005.

${ }^{7}$ KAYE, D. H., The double helix..., cit.

${ }^{8}$ STR es la abreviación de Short Tandem Repeat (secuencia corta repetida en tándem). Dichas secuencias de DNA (generalmente de 4 o 5 nucleótidos) se encuentran repetidas de forma contigua un número variable de veces. Existen de muchos tipos distribuidas por todo el genoma.

${ }^{9}$ Muchas veces se utiliza banco o base de datos como sinónimos. Sin embargo, nosotros somos favorables a utilizar la nomenclatura de Houck and Siegel (2006) donde un banco de datos es una colección de perfiles genéticos de personas, mientras que base de datos se refiere a una recopilación poblacional de las frecuencias génicas de los alelos para los diferentes marcadores (por ejemplo, STR). HOUCK, M.M., SIEGEL, J.A., Fundamentals of Forensic Science. Elsevier Academic Press, Burlington (MA), USA, 2006.

${ }^{10}$ Este perfil genético se ha obtenido a partir de una 'muestra indubitativa' ya que se conoce la identidad exacta de la persona a la que pertenece.

11 VIVES-REGO, J., "Environmental Forensics: a scientific service at the service of Justice and Society". Environ. Forensics, vol. 5, 2004, pp.123-124.
} 
Justicia y quizás en menor medida ha mejorado la moral pública y la disciplina social a través de su capacidad disuasoria.

Nuestro país no se quedó a la zaga respecto al uso del DNA en investigación policial ${ }^{12}$ y también en la implementación de los bancos de datos basados en esta tecnología. Una historia resumida de los principales acontecimientos en dicho ámbito referidos a España puede encontrarse en la memoria del Centro Tecnológico de Seguridad ${ }^{13}$. Es de destacar que la aprobación de la Ley Orgánica 10/2007, de 8 de octubre, permitió la puesta en marcha de la Base de Datos Nacional de ADN en nuestro país. Siguiendo el modelo organizativo norteamericano en España existe un Base de Datos Nacional (SDIS, abreviación de State DNA Index System) conectada con las bases de datos institucionales de tipo local (LDIS, es decir, Local DNA Index System). Estas últimas son operadas por la Comisaría General de la Policía Científica (Policía Nacional), el Servicio de Criminalística de la Guardia Civil, el Instituto Nacional de Toxicología y Ciencias Forenses, la División la Policía Científica del Cos Mossos d'Esquadra - Policia de Catalunya, la División la Policía Científica de la Policía Foral de Navarra y Unidad de la Policía Científica de la Ertzaintza ${ }^{13}$. Todas sus actividades están sujetas a la legislación, inicialmente a la Ley Orgánica 15/1999, de 13 de diciembre, de Protección de Datos de Carácter Personal y posteriormente a La Ley Orgánica 3/2018, de 5 de diciembre, de Protección de Datos Personales y garantía de los derechos digitales. También se ajustan a La Ley Orgánica 10/2007, de 8 de octubre, reguladora de la base de datos policial sobre identificadores obtenidos a partir del ADN, que hemos citado anteriormente. También están sujetas a las decisiones de la CNUFADN (Comisión Nacional para el uso forense del $\mathrm{ADN})^{14} \mathrm{y}$ a las recomendaciones del ENFSI-DNAWG (European Network of Forensic Science Institutes - DNA - Working Group).

\section{DESCRIPCIÓN DE LOS DISTINTOS TIPOS DE BANCOS DE DATOS BASADOS EN EL DNA}

Existen diferentes tipos de bancos de datos de DNA, aunque no todos son utilizados en el ámbito policial o jurídico. Desde hace unos años han proliferado distintas empresas privadas que por una módica cantidad de dinero analizan el perfil genético personal ${ }^{15}$ y lo comparan con otros preexistentes en su banco para buscar relaciones de parentesco o de origen étnico. También a nivel de investigación en genética clínica se puede generar bancos de DNA con el material genético de personas afectadas por una cierta enfermedad y de otras que pueden ser familiares suyos o controles de la población general. Además, en los bancos de datos se puede tener la información de perfiles genéticos para usos judiciales que no pertenecen al ámbito criminal. Un ejemplo de estos últimos son los bancos de DNA denominados 'de interés humanitario' y sirven para identificar personas desaparecidas o restos de cuerpos ocasionados en catástrofes, actos terroristas o conflictos bélicos. También contienen, aunque en un fichero informático diferente,

\footnotetext{
12 MONTES, F. "El ADN en la investigación criminal”, Boletín del Instituto Universitario de Investigación sobre Seguridad Interior, 2005, pp. 1-10.

${ }^{13}$ CENTRO TECNOLÓGICO DE SEGURIDAD, Base de datos policial de identificadores obtenidos a partir de ADN, Ministerio del Interior, Secretaría de Estado de Seguridad, Madrid, 2019. Accesible desde la web: https://cpage.mpr.gob.es/producto/base-de-datos-policial-de-identificadores-obtenidos-a-partir-de-adn-2/ (consultada el 30 de octubre de 2021).

${ }^{14}$ Para conocer el tipo de acciones que realiza dicha Comisión recomendamos la consulta del documento: COMISIÓN NACIONAL PARA EL USO FORENSE DEL ADN. Actividades 2009-2012, Ministerio de Justicia, Secretaría General Técnica, Madrid, 2011. Dicha Comisión publica bianualmente un resumen de las actividades que lleva a cabo.

${ }^{15}$ En estos casos se utiliza habitualmente como marcador genético los SNP (single nucleotide polymorphism, que se traduce como polimorfismo de nucleótido único). Son muy abundantes a nivel del genoma humano y especialmente útiles en diferentes áreas de la investigación genética.
} 
los perfiles genéticos de los familiares de dichos individuos para poder identificarlos por comparación de perfiles (estudios genéticos de parentesco).

Queremos hacer notar que a partir de las muestras biológicas que se recogen podemos tener dos tipos de información genética que se puede almacenar: el DNA total de una persona en forma de moléculas que se guardan en un tubo (material molecular) o un fichero informático en el cual se registra la información genética para unos genes (o marcadores genéticos) concretos de una persona (información digitalizada). El primer tipo de información consiste en la obtención (proceso técnicamente denominado extracción) del DNA a partir de una muestra biológica (sangre, saliva, etc.). Con ella tenemos todo el genoma de una persona concreta lo que, por ejemplo, nos permite estudiar una enfermedad si estamos realizando un estudio sobre las causas genéticas de la misma. Pero también podremos saber muchas más cosas de las personas que han donado su material biológico: su perfil genético para STR de interés policial, su predisposición a tener otras enfermedades, estimar sus características fenotípicas (aspecto) respecto al color del cabello, el de los ojos, la estatura, etc. De manera que tener el DNA total de una persona es hoy en día relativamente fácil y constituye una riqueza por sí misma difícil de valorar, puesto que pueden facilitar un conocimiento amplio y profundo de esa persona, teniendo por tanto trascendencia individual y social. Las colecciones de extracciones de DNA de diferentes personas pueden ser muy tentadoras, ya que pueden usarse para el fin propuesto en el estudio, pero para muchas cosas más. Por otra parte, los ficheros informáticos que contienen la información genética para diversos marcadores, también pueden utilizarse para otras actividades distintas para las que fueron generadas. Por ejemplo, un cuerpo policial puede estar buscando el perfil genético de un sospechoso en los bancos de datos policiales (locales, estatales o con autorización expresa internacional). Al no encontrar ninguna coincidencia ('match') entre el perfil genético del sospechoso y los registrados en dichos bancos, podría tenerse la tentación, por ejemplo, de realizar la búsqueda en los bancos de DNA de 'interés humanitario'. Todos los países tienen legislación respecto a la privacidad de los datos y la confidencialidad de las búsquedas. También existe un marco legal indicando con precisión qué actividades pueden o no desarrollar las personas al cargo de los bancos de datos de DNA de índole policial.

\section{PERMANENCIA DE LA INFORMACIÓN EN LOS BANCOS DE DATOS}

Una pregunta fundamental desde un punto de vista ético es ¿cuánto tiempo deben conservarse las muestras personales de DNA o los perfiles genéticos recopilados en ficheros informáticos? Tener el DNA total extraído de las personas puede permitir la posterior reanálisis para nuevos marcadores o genes, lo cual a su vez puede tener mucho interés por ejemplo si se realiza una búsqueda internacional de perfiles. Como diversos países difieren en los STR que utilizan, se puede reanalizar el DNA extraído para tener el perfil genético de los STR que interesen para la investigación internacional. Mantener un perfil genético en un fichero informático durante mucho tiempo puede tener relevancia policial, incluso después de que una persona haya muerto. Nos gustaría presentar un ejemplo de este último caso. Imaginemos que existe un asesino en serie que no ha podido ser nunca identificado, que había actuado antes o poco después de la introducción del DNA en la práctica forense y que se considera un caso abierto ('cold case' en inglés). Este asesino ha dejado de actuar, pero queda la duda de saber si volverá a hacerlo o no. Finalmente, un investigador encuentra nuevos vestigios biológicos del sospechoso a partir de pruebas recogidas en el lugar de los hechos y que se habían preservado, se puede extraer suficiente DNA y obtener un perfil genético que hasta el momento no se había conseguido. Entonces se puede realizar la búsqueda en los bancos de datos policiales. Imaginemos primero que podría obtenerse un 'match' con una persona de una cierta edad, con lo cual podría investigarse su vinculación con el caso. En este caso se trata de un hecho socialmente relevante, ya que 
finalmente, y después de muchos años, se ha podido encontrar al sospechoso de ser un asesino en serie. Pero imaginemos ahora otra situación: que se obtuviese una coincidencia de perfiles entre el obtenido a partir del lugar de los hechos y una persona ya fallecida. Se debería investigar entonces la posible vinculación de dicho individuo con los sucesos que se investigan y supongamos que finalmente puede relacionarse. En este segundo caso también se ha identificado el sospechoso y, como ya ha desaparecido, tenemos la certeza de que no se producirán más crímenes por su causa. En ambas situaciones la repercusión social es enorme puesto que se logra resolver con éxito un caso que había estado abierto durante muchos años. En el segundo caso, si el asesino en serie hubiese muerto y no se hubiese guardado en el banco de datos su perfil, nunca se hubiese sabido su identidad ni la certeza de ya no podría volver a actuar. Es decir, una adecuada utilización de los bancos de datos policiales además de proteger a la sociedad en su conjunto actúa como elemento disuasorio del crimen y refuerza los valores éticos de las sociedades presentes y futuras.

En esta línea de proceder, en Norteamérica toda la población reclusa debe donar su DNA y éste se preserva en las denominadas fichas FTA que estabilizan la molécula y se pueden reanalizar años después si fuese necesario. También se almacenan sus perfiles genéticos para los STR en los correspondientes bancos de datos policiales ${ }^{16},{ }^{17},{ }^{18}$.

Dichos bancos de datos van creciendo a lo largo de los años al irse introduciendo nuevos perfiles genéticos, tanto de personas como de los recuperados en el lugar de los hechos. En muchos países dichos bancos pueden ser enormes y contener millones de datos ${ }^{19}$. Ello permite resolver muchos delitos, algunos muy graves causantes de alarma social y actuar como elemento disuasorio del crimen. Por tanto, se puede concluir que su uso ha sido y es eficaz, socialmente útil y éticamente deseable ${ }^{20},{ }^{21},{ }^{22},{ }^{23},{ }^{24},{ }^{25}$.

Sin embargo, persisten más cuestiones de tipo ético que son fundamentales ¿Cuál debe ser el criterio por el que una persona debe incluirse en un banco de datos policial de DNA? Actualmente esos criterios son distintos dependiendo de cada país ${ }^{26}$. Otras preguntas que se pueden plantear son: ¿una persona que fue arrestada por conducir un día bajo los efectos del alcohol, debe mantenerse su perfil genético de por vida en un banco de datos policial junto al de criminales o convictos? ¿Merece dicha persona esta especie de 'sentencia infinita' si nunca más ha cometido un delito? ¿Tiene derecho a redimirse y poder ser anulado su perfil del banco de

${ }^{16}$ BUTLER, J.M., Forensic DNA..., cit.

17 GOODWIN, W., LINACRE, A., HADI, S., An introduction to Forensic Genetics, John Wiley and Sons, Ltd. Chichester, UK, 2007.

${ }_{18}$ MESTRES, F., VIVES-REGO, J., "Bancos y bases de datos genéticos para usos forenses”, Rev. Poder Judicial, núm. 89, 2009b, pp. 239-263.

19 ASPLEN, C., "DNA databases", en PRIMORAC, D., SCHANFIELD, M. (Eds.) Forensic DNA applications: an interdisciplinary perspective, CRC Press, Boca Raton (FL), USA, 2014, pp. 557-569.

${ }^{20}$ BUTLER, J.M., Forensic DNA..., cit.

${ }^{21}$ GOODWIN, W., LINACRE, A., HADI, S., An introduction to..., cit.

22 MESTRES, F., VIVES-REGO, J., “Bancos y bases...”, cit.

${ }^{23}$ WALSH, S.J., CURRAN, J.M., BUCKLETON, J.S., "Modeling forensic DNA database performance”, J. Forensic Sci., vol. 55, 2010, pp. 1174-1183.

${ }^{24}$ BUTLER, J.M., Forensic DNA..., cit.

${ }^{25}$ MESTRES, F., ZIVANOVIC, G., "Some applications of DNA databanks as an investigative tool for solving criminal cases", J. Criminal. and Law, vol. 23, 2018, pp. 233-250.

26 ALONSO, A., "Las bases de datos de ADN de interés forense", en CRESPILLO, M.C., BARRIO, P.A. (Ed.), Genética forense: del laboratorio a los tribunales, Ediciones Díaz de Santos, Madrid, 2019, pp. 425-443. 
datos? Un caso, si cabe más grave, era el de retener en los bancos de datos los perfiles genéticos de personas detenidas en cuyo juicio la sentencia las declaró 'no culpables' o 'inocentes' ${ }^{27}$. A ese respecto es de destacar el veredicto unánime al que llegó la Gran Sala del Tribunal Europeo de Derechos Humanos en 2008 respecto el caso Marper ${ }^{28}$. Según dicha Corte la retención indefinida de perfiles de ADN de personas consideradas 'no culpables', así como de huellas dactilares y muestras biológicas violaban el artículo 8 del Convenio Europeo sobre Derechos Humanos, en concreto respecto al derecho al respeto de la vida privada y familiar. Como consecuencia de dicha sentencia más de 1,7 millones de perfiles genéticos de personas declaradas 'no culpables' se retiraron del banco de datos policial del Reino Unido (el denominado NDNAD) en 2013. También más de 7,75 millones de muestras de DNA fueron destruidas.

\section{LAS BÚSQUEDAS FAMILIARES}

Cuando se realizan búsquedas en los bancos de datos policiales, a veces no se encuentra una coincidencia completa, pero si se pueden detectar informáticamente perfiles genéticos similares a los que se buscan. Dichos genotipos pueden pertenecer a familiares de sospechosos. Realizar dicha investigación se denomina "búsqueda familiar". Evidentemente a mayor parentesco mayor será la similitud de perfiles. Así y para los genes de cromosomas no sexuales ( $\mathrm{X}$ e $\mathrm{Y}$ ) los hermanos comparten como promedio el 50\% de su material genético. En las comparaciones entre un progenitor (padre o madre) respecto a un descendiente (hijo o hija) también se comparte como promedio el 50\% del material genético, pero además en tales casos al menos un alelo de cada marcador estudiado debe coincidir entre progenitor y descendiente. Las búsquedas familiares han logrado resolver casos difíciles y arrestar a criminales peligrosos ${ }^{29},{ }^{30},{ }^{31}$. Sin embargo, presentan problemas éticos y legales considerables ${ }^{32}$. Como hemos comentado la búsqueda familiar no persigue encontrar coincidencias completas y cuando se realiza en bancos de datos enormes se genera un gran número de sospechosos potenciales. Es lógico, ya que a este nivel existirán bastantes personas sin vínculos familiares que compartirán un número elevado de alelos de los marcadores genéticos. Por esta razón la mayoría de los sospechosos potenciales son inocentes y no guardan relación con el caso que se investiga. En tales circunstancias, se está invadiendo la privacidad de dichas personas, pueden generarse problemas de índole doméstica y alarma social injustificada. Esto sucede de hecho cuando se presenta la policía en el domicilio de un supuesto sospechoso, para investigarlo sin pruebas que lo relacione con el caso. En la mayoría de países la legislación no respalda este tipo de actuaciones. Es difícil encontrar un consenso respecto a qué tipo de delitos es susceptible de aplicar una investigación basada en búsquedas familiares en bancos de datos de DNA y cómo articular una legislación adecuada ${ }^{33}$. En cualquier

\footnotetext{
${ }^{27}$ Esta distinta valoración depende del sistema judicial de cada país.

${ }^{28}$ Sentencia del Tribunal Europeo de Derechos Humanos, de 4 de diciembre de 2008, caso S. y Marper v. Reino Unido (Aplicaciones $\mathrm{n}^{\circ}$ 30562/04 y 30566/04). Accesible desde la web: https://rm.coe.int/168067d216 (consultada el 30 de octubre de 2021).

${ }^{29}$ MILLER, G., "Familial DNA testing scores a win in serial killer case”, Science, vol. 329, 2010, pp. 262.

${ }^{30}$ KRIMSKY, S., SIMONCELLI, T., Genetic Justice, Columbia University Press, N.Y., 2011.

${ }^{31}$ MESTRES, F., VIVES-REGO, J., "Bancos y bases...”, cit.

32 GARCÍA, O., CRESPILlO, M., YURREBASO, I., "Suspects identification through 'familial searching' in DNA databases of criminal interest. Social, ethical and scientific implications", Rev. Esp. Med. Legal, vol. 43, 2017, pp. 2634.

${ }^{33}$ BARCA, D.C., "Familiar DNA testing, House Bill 3361, and the need for federal oversight". Hastings Law Journal, núm. 64, 2013, pp.499-527.
} 
caso, es inexcusable la utilización de la Ética y la Axiología en la aprobación de la legislación definitiva.

\section{LAS BÚSQUEDAS FAMILIARES DE LARGO ALCANCE}

Los avances tecnológicos, tanto de la secuenciación como de su análisis bioinformático, ha llevado a una reducción de los costes en los análisis del DNA. Además, su uso se ha ido popularizando gracias a aparecer constantemente en los medios de comunicación. Esta situación, ha conducido a que diferentes empresas privadas presten sus servicios de secuenciación y análisis por una módica cantidad de precio a sus clientes para que estos puedan encontrar posibles familiares lejanos (obteniendo genealogías) o el origen étnico de sus ancestros. Todo ello ha originado que se constituyan grandes bancos de datos con la información genética de muchas personas. En 2018 se estimaba que unos 15 millones de personas habían donado su DNA a este tipo de compañías ${ }^{34}$. Estos bancos de datos son accesibles con solo registrarse. Su existencia permitió lo que se denomina 'long-range familial searches', que se puede traducir como búsquedas familiares de largo alcance. Realizando una búsqueda en uno de dichos bancos la policía, con la ayuda de la genealogista Barbara Rae-Venter, pudo identificar y detener a Joseph James DeAngelo, el tristemente famoso asesino del Golden State, que actuó en California entre 1973 y 1986 robando, violando y matando. La detención tuvo lugar en 2018, cuando DeAngelo tenía 72 años. El procedimiento utilizado para su identificación y arresto tuvo una gran repercusión mediática, pero no quedó exento de generar una amplia preocupación a nivel ético y legal ${ }^{35}$. La policía había realizado una búsqueda familiar clásica en los bancos de datos policiales sin resultado. Entonces decidieron buscar similitudes de perfiles en bancos de datos genealógicos públicos. En concreto utilizaron el denominado GEDmatch. Es de destacar que cuando se accede a él aparece una frase que advierte a los posibles usuarios que los datos que contiene pueden ser potencialmente utilizados en investigaciones criminales que se fundamenten en una orden o citación judicial $^{36}$. La policía pudo detectar en él a un familiar lejano de DeAngelo y la posterior investigación policial condujo a la detención de este último. El perfil genético de DeAngelo coincidía con el del asesino del Golden State, ya que se había analizado DNA del agresor recogido en el lugar de los hechos. En este caso se resolvió un problema técnico interesante: los bancos de datos de DNA policiales utilizan como marcadores genéticos los STR mientras que los genealógicos o de etnicidad usan los SNP. Así, existen procedimiento para poder realizar búsquedas cruzadas entre STR y SNP reconociendo pequeñas regiones cromosómicas idénticas heredadas a partir de un antepasado común ${ }^{37},{ }^{38}$. Esta nueva aproximación experimental se ha utilizado posteriormente para resolver diversos $\operatorname{casos}^{39}$, de manera que sólo en 2018 lo fueron

${ }^{34}$ ERLICH, Y., SHOR, T., PE'ER, I., CARMI, S., "Identity inference of genomic data using long-range familial searches", Science, vol. 362, 2018, pp. 690-694.

${ }^{35}$ SCUDDER, N., MCNEVIN, D., KELTY, S.F., FUNK, C., WALSH, S. J., ROBERTSON, J., "Policy and regulatory implications of the new frontier of forensic genomics: direct-to-consumer genetic data and genealogy records", Curr. Issues Crim. Justice, vol 31, 2019, pp.194-216.

${ }^{36}$ Esta advertencia puede leerse en la página web siguiente. https://www.gedmatch.com/tos.htm (consultada el 26 diciembre 2020).

${ }^{37}$ KIM, J., EDGE, M.D., ALGEE-HEWITT, B.F.D., LI, J.Z., ROSENBERG, N.A., "Statistical detection of relatives typed with disjoint forensic and biomedical loci”, Cell, vol. 175, 2018, pp. 848-858.

${ }^{38}$ GARCÍA, O., CRESPILLO, M., YURREBASO, I., "Suspects identification through...”, cit.

39 Una revisión en detalle de los procedimientos genéticos de las búsquedas familiares de largo alcance puede encontrarse en GREYTAK, E.M., MOORE, C., ARMENTROUT, S.L., "Genetic genealogy for cold case and active investigations”, Forensic Science International, vol. 299, 2019, pp. 103-113. 
doce más ${ }^{40}$. En ellos la policía contó con la ayuda de John Doe Project (organización sin ánimo de lucro que trata de buscar personas desaparecidas) y de la empresa Parabon NanoLabs (dedicada a estimar fenotipos y a otros servicios basados en el DNA para las fuerzas de seguridad). Según fuentes de la propia compañía, ésta ha trabajado e investiga centenares de casos. Sin embargo, estos procedimientos se llevan a cabo a pesar de no existir legislación al respecto, conculcan gravemente los derechos y la privacidad individual y suscitan una gran preocupación a nivel ético ${ }^{41},{ }^{42}$. En estas circunstancias, se considera éticamente necesario acotar que delitos podrían investigarse mediante el procedimiento que hemos presentado. Desarrollar este tipo de legislación, en la que deben implicarse genetistas forenses y miembros de la judicatura ${ }^{43}$, está pendiente.

En cualquier caso, somos del parecer que este tipo de actuaciones policiales y forenses deberían considerarse éticamente aceptables puesto que permiten, a los perjudicados por las acciones criminales en acto o en potencia, estar más protegidos. En relación con el derecho de la privacidad, consideramos que los derechos de una mayoría deben prevalecer sobre el de unos pocos, especialmente cuando se trata de delitos graves tipificados en el código penal.

\section{LOS DRAGNETS O 'PESCA DE ARRASTRE'}

Un dragnet, que en castellano podríamos traducir como una 'pesca de arrastre', consiste en tratar de encontrar un sospechoso en un caso donde la práctica policial hasta el momento no ha proporcionado ninguno. La idea es simple, analizar un amplio colectivo de personas respecto a su perfil genético para ver si por casualidad se encuentra el mismo que el recuperado en el lugar de los hechos o, al menos, el de un familiar cercano (búsqueda familiar). Existen dos formas de realizar el dragnet, o bien pidiendo la donación voluntaria del DNA a las personas o bien mediante una orden judicial. Históricamente el primer ejemplo de dragnet fue el caso Pitchfork (1986) donde dos chicas fueron asesinadas en diferentes años. Se sabía el perfil genético del agresor, pero no se encontró ningún sospechoso. El Forensic Science Service planificó un análisis masivo de más de 4.580 varones de la comarca para conocer su perfil genético y compararlo con el del agresor. Pitchfork intentó evadir el análisis proponiendo a otra persona que se presentase a donar el DNA en su lugar, pero ésta última informó a la policía de la proposición que había recibido. Por esta razón Pitchfork pudo ser detenido, demostrándose posteriormente que su perfil coincidía con el del autor de los crímenes ${ }^{44},{ }^{45}$. En España este procedimiento de investigación se utilizó en el caso Eva Blanco ${ }^{46}$. Sin embargo, los dragnets son en la práctica económicamente muy costosos

\footnotetext{
${ }^{40}$ ERLICH, Y., SHOR, T., PE'ER, I., CARMI, S., "Identity inference of genomic...”, cit.

${ }^{41}$ CALLAWAY, E., "Privacy concerns over DNA used for crime investigation”, Science, vol. 562, 2018, pp. 315-316.

42 RAM, N., GUERRINI, C.J., MCGUIRE, A.L., "Genealogy databases and the future of criminal investigation", Science, vol. 360, 2018, pp. 1078-1079.

${ }^{43}$ CALLAGHAN, T.F., "Responsible genetic genealogy”, Science, vol. 366, 2019, pp. 155.

44 JEFFREYS, A.J., "Genetic fingerprinting”, cit.

${ }^{45}$ KAYE, D. H., The double helix..., cit.

46 ÁLVAREZ DE NEYRA, S., "Los nuevos avances en la determinación genética. De las bases de datos al fenotipado forense. El caso de Eva Blanco", Auctoritas Prudentium, vol. X, núm. 18, 2018, pp. 1-29.
} 
y generalmente ineficientes ${ }^{47},{ }^{48},{ }^{49},{ }^{50}$. Además, generan gran preocupación respecto a si conculcan las libertades civiles y es ahí donde deseamos mostrar las contradicciones cuando no dilemas que pueden darse en este tipo de situaciones. En primer lugar, los dragnets no están generalmente jurídicamente reconocidos. Es más, muchas veces se llevan a cabo sin una orden judicial, basándose en indicios de sospecha insuficientes. En determinadas circunstancias, es probable que la policía ejerza coacción a diferentes niveles para poder conseguir las muestras de DNA. Si una persona se niega a dar voluntariamente su DNA (y a fecha de hoy se reconoce ese derecho), pasa a ser considerada como sospechosa. Además, existen otras consideraciones a tener en cuenta. Por ejemplo, ¿puede la policía retener los perfiles genéticos de las personas que han donado su DNA más allá de la resolución del caso? Es decir, ¿es lícito y/o legal mantener un banco de datos de muestras de DNA y de perfiles genéticos de personas que las han donado voluntariamente para otra finalidad? Es evidente que negarse a proporcionar una muestra de DNA no es sinónimo de admitir la culpabilidad de un caso, pero parece inevitable que la sospecha de la policía, vecinos, amigos y familia recaiga indefectiblemente sobre dicha persona.

\section{BANCOS DE DATOS DE DNA UNIVERSALES}

Los responsables de las fuerzas de seguridad querrían tener bancos de datos de DNA lo más amplios posibles de forma que se pudiesen identificar fácilmente a la mayoría de los sospechosos de haber cometido algún delito. También políticos y algunos investigadores han propuesto bancos de datos de DNA que contengan los perfiles genéticos de todos los habitantes de un país ${ }^{51}$. Su argumentación es la siguiente: "si una persona no piensa cometer ningún delito a lo largo de su vida, qué problema puede tener en donar su DNA para un banco de datos policial". En primer lugar, nos gustaría mostrar la existencia de diferentes situaciones de cariz técnico que pueden conducir a identificaciones incorrectas como sospechosas a personas que no los son en base a los perfiles genéticos. El primer tipo de error se detectó poco después de instaurarse el NDNAD en el Reino Unido. En 1999 se produjo un robo y en el lugar de los hechos se pudo recuperar el perfil genético del sospechoso ${ }^{52}$. La comparación de este perfil genético con los almacenados hasta entonces en el NDNAD produjo una coincidencia. El perfil del banco de datos correspondía al Sr. R. Easton, que había tenido que donar su DNA al banco en el marco de una investigación en caso de una disputa familiar en 1995. Por aquel entonces se utilizaban solamente 6 marcadores STR y la probabilidad ${ }^{53}$ de encontrar dicho perfil genético por azar entre personas no emparentadas en la población de referencia se estimó en 1 en 37 millones. Es de destacar que al producirse dicho delito el Sr. Easton padecía de Parkinson, no podía andar más de 10 metros sin ayuda y que el robo tuvo lugar a unos $250 \mathrm{~km}$. de su domicilio. El análisis de marcadores STR adicionales pusieron de manifiesto el error. Es recomendable, como muchos técnicos forenses policiales constantemente recuerdan, que, una vez identificado un sospechoso gracias a un banco

\footnotetext{
${ }^{47}$ WALKER, S., "Police DNA ‘sweeps' extremely unproductive”, Dept. Criminal Justice, University of Nebraska at Omaha, 2004.

${ }^{48}$ ESMAILI, S., "Searching for a needle in a haystack: the constitutionally of police DNA dragnets", Chicago-Kent Law Review, vol. 82, 2007, pp. 495-523.

${ }^{49}$ MESTRES, F., ZIVANOVIC, G., "Some applications of DNA...”, cit.

${ }^{50}$ KRIMSKY, S., SIMONCELLI, T., Genetic Justice, cit.

${ }^{51}$ WALLACE, H.M., JACKSON, A.R., GRUBER, J., THIBEDEAU, A.D., "Forensic DNA databases-Ethical and legal standards: A global review", Egypt. J. Forensic Sci., vol. 4, 2014, pp. 57-63.

52 GILL, P., "DNA evidence and miscarriages of justice", Forensic Sci. Intern., vol. 294, 2019, pp. e1-e3.

${ }^{53}$ Esta probabilidad se denomina en inglés random match probability o R.M.P., terminología frecuentemente utilizada en genética forense sin traducirse al castellano.
} 
de datos, los investigadores de la policía deben averiguar su posible vinculación con el caso antes de proceder a su detención. Muchas veces el temor a que pueda escapar y la presión social pueden llevar a la precipitación. Otra fuente de error es que en el lugar de los hechos se recoja material biológico (del cual se pueda extraer DNA) perteneciente a una persona y depositado con anterioridad a que tuviese lugar el acto delictivo. Este hecho podría inculpar erróneamente a un individuo no relacionado con dicho delito. En cierto modo y relacionado con lo anterior está el fenómeno denominado secondary transfer (transferencia secundaria), por el cual el DNA de una persona no involucrada en una situación delictiva se ha transferido por contacto a un intermediario (objeto o persona) y de éste a superficies (humanas o no) del lugar de los hechos. Esta situación es debida a que las tecnologías actuales pueden amplificar el DNA para su análisis a partir de cantidades iniciales muy pequeñas. Se conocen diversos ejemplos y es un tema que ha requerido la atención de los genetistas forenses ${ }^{54},{ }^{55}$. También se debe tener presente que, aunque se tomen las debidas precauciones, el riesgo de contaminación siempre existe ya que, como acabamos de comentar, a partir de muy poca cantidad inicial de DNA se puede obtener un perfil genético. Finalmente está el fenómeno de la estructuración poblacional, debida a la historia de las poblaciones humanas en especial si derivan de pocos individuos iniciales y presentan ciertos niveles de consanguinidad. En estas situaciones no todas las combinaciones son igual de probables, sino que algunas pueden ser más corrientes. Anteriormente, al definir conceptualmente la random match probability ya se ha tenido en cuenta esta posibilidad. Por la propia naturaleza del método científico nunca tenemos la certeza de lo que investigamos, por tanto, aunque un perfil genético sea improbable de encontrar no podemos descartar su existencia ${ }^{56}$.

$\mathrm{El}$ auge de los bancos de datos donde las personas pueden donar su DNA para fines genealógicos o para averiguar sus orígenes étnicos ha reabierto el debate sobre un banco de datos universal de DNA de uso policial, con argumentos a favor y en contra ${ }^{57},{ }^{58}$. Entre los postulados para defenderlos estarían los siguientes: el uso de unos 20 STR permitiría resolver y por tanto prevenir delitos graves, evitaría que los gobiernos autorizasen búsquedas familiares de largo alcance y el uso de bancos de datos de DNA no policiales para la investigación de delitos. Este banco de datos universal no sería discriminatorio como los actuales (fenómeno confirmado en los del Reino Unido y los Estados Unidos de Norteamérica) y finalmente se eliminaría el estigma de estar incluido en un banco de datos policial. Además podrían tomarse una serie de medidas para evitar malos usos y suspicacias: estos bancos de datos deberían depender de agencias independientes y el acceso siempre debería realizarse bajo orden judicial, la muestras físicas de DNA deberían destruirse después de haber obtenido la información genética necesaria, las medidas de seguridad tendrían que ser elevadas y castigar debidamente a los infractores que realizasen un uso no adecuado y evidentemente sería imprescindible establecer un correcto marco legal. Entre los argumentos en contra cabría destacar: un banco de datos universal de perfiles de DNA sería muy caro de establecer y mantener, afectaría claramente la privacidad de las personas, también podría dañar la imagen de la Genética como ciencia al presentarse como un instrumento

\footnotetext{
${ }^{54}$ CALE, C.M., EARLL, M., LATHAM, K.E., BUSH, G.L., "Could secondary DNA transfer falsely place someone at the scene of a crime?", J. Forensic Sci., vol. 61, 2016, pp. 196-203.

${ }^{55}$ CALE, C.M., "Forensic DNA evidence is not infallible", Nature, vol. 526, 2015, pp. 611.

${ }^{56}$ Una situación en la que dos personas tienen el mismo perfil genético es la de los gemelos monocigóticos o idénticos. Si bien por las huellas dactilares se pueden diferenciar, su identificación mediante técnicas de genética molecular fue un gran reto. Actualmente se pueden diferenciar dos gemelos de este tipo por medio de los patrones epigenéticos de metilación o de mutaciones somáticas una vez se han separado en el interior del claustro materno.

${ }^{57}$ HAZEL, J.W., CLAYTON, E.W., MALIN, B.A., SLOBOGIN, C., "Is it time for a universal genetic forensic database?”, Science, vol. 362, 2018, pp. 898-900.

${ }^{58}$ JOLY, Y., MARROCCO, G., DUPRAS, C., "Risks of compulsory genetic databases”, Science, vol. 363, 2019, pp. 938.
} 
de control de los individuos y finalmente atentaría contra un pilar fundamental de la democracia: la presunción de inocencia.

\section{CONCLUSIONES Y PERSPECTIVAS DE FUTURO}

En este punto es imprescindible ser conscientes que hemos pasado de la Genética forense a la Genómica forense. Los avances de las nuevas tecnologías de secuenciación de los genomas y la generalización de su uso han conllevado una reducción de los costes, de manera que no es impensable poder disponer de los genomas completos secuenciados de personas concretas en un futuro próximo. Estos avances abrirían un espectro más amplio de la investigación policial: a partir de una muestra de DNA recogida en el lugar de los hechos se podría secuenciar el genoma $\mathrm{y}$, además de saber el perfil genético para una amplia colección de marcadores genéticos (STR u otros), se podrían estimar una serie de características físicas del sospechoso (color del cabello, de los ojos, edad, estatura, etnicidad, predisposición a enfermedades genéticas, aspecto facial, etc.). Se ha utilizado el verbo 'estimar' ya que la relación entre los genes y el aspecto (fenotipo) para una serie de características físicas no es directa y la gran mayoría dependen en mayor o menor medida del ambiente ${ }^{59},{ }^{60}$. En este contexto, ambiente se define como el conjunto de todos aquellos factores no genéticos que tienen un efecto sobre el aspecto final o fenotipo de la característica que se está estudiando.

En resumen, como se ha comentado a largo del artículo el genoma de una persona contiene una enorme cantidad de información que puede ser muy codiciada y utilizada para usos fraudulentos cuando no malintencionados. Como ciudadanos hemos de estar atentos al buen uso de la genética y la genómica en el ámbito de la criminalística, pero también en el de las empresas que por un precio asequible ofrecen sus servicios de genealogía, origen étnico u otros, ya que poseerán información de todo el genoma y hay que evitar que puedan utilizar esos datos para donarlos a terceros con otros fines ${ }^{61},{ }^{62}$. En este último ámbito hay que esclarecer con el mayor rigor posible las condiciones de otros posibles usos del DNA que se ha enviado a la empresa. En nuestra sociedad actual, en la que tanto se habla y se dice defender nuestra privacidad, no es menos cierto que ésta se encuentra constantemente amenazada. Es nuestra obligación ética y moral defenderla en cualquier circunstancia, especialmente cuando no haya menoscabo de la seguridad pública y de la correcta administración de la Justicia. Sin embargo, entendemos (o somos de la opinión) que el derecho a la privacidad no puede estar axiológicamente por encima del derecho a estar protegidos a través del código penal, especialmente en relación con aquellos delitos criminales que dañan gravemente a las personas tanto a nivel moral como material. En este sentido, se hace necesario un profundo estudio de la jerarquización axiológica ${ }^{63}$ de los derechos que se protegen y se conculcan en los continuos avances de la Genética Forense.

\footnotetext{
${ }^{59}$ MESTRES, F., "La utilización del concepto de ADN en nuestra sociedad: tecnociencia, frases hechas y errores científicos", Sociol. Tecnol., vol. 2, 2012, pp. 33-43.

60 MESTRES, F., VIVES-REGO, J., "Identificación de características forenses avanzadas a partir del ADN: etnogeografía, patología delictiva y morfoanatomía”, La Ley Penal, núm. 91, 2012, pp. 48-56.

${ }^{61}$ NIEMIEC, E., HOWARD, H. C., "Ethical issues in consumer genome sequencing: Use of consumers' samples and data", Appl. Transl. Genom., vol. 8, 2016, pp. 23-30.

${ }^{62}$ MARFANY, G., “¿Quién quiere tu ADN?”, Mètode U.V., vol. 104, 2020, pp. 99.

${ }^{63}$ En este trabajo entendemos por axiología como la teoría de los valores y a la consecuente jerarquización de los valores morales, más allá de que deba aceptarse que todo reconocimiento de valor moral y filosófico es a priori abstracto, mientras no se conozcan las relaciones de valor y en el caso concreto que nos ocupa, entre las consecuencias de la aplicación de la Genética Forense. Para más detalles sugerimos la obra básica: HARTMANN, N., Ética, Ediciones Encuentro S.A., Madrid, 2011, especialmente el capítulo 28 "De la jerarquía de los valores". Para una aproximación a la "teoría filosófica de valor" y los debates a que da lugar sugerimos la consulta de las siguientes páginas web:
} 


\section{BIBLIOGRAFÍA}

- ALONSO, A., "Las bases de datos de ADN de interés forense", en CRESPILLO, M.C., BARRIO, P.A. (Ed.), Genética forense: del laboratorio a los tribunales, Ediciones Díaz de Santos, Madrid, 2019, pp. 425-443.

- ÁlVAREZ DE NEYRA, S., "Los nuevos avances en la determinación genética. De las bases de datos al fenotipado forense. El caso de Eva Blanco", Auctoritas Prudentium, vol. X, núm. 18, 2018, pp. 1-29.

- ASPLEN, C., "DNA databases", en PRIMORAC, D., SCHANFIELD, M. (Eds.) Forensic DNA applications: an interdisciplinary perspective, CRC Press, Boca Raton (FL), USA, ,2014, pp. 557-569.

- BARCA, D. C., "Familiar DNA testing, House Bill 3361, and the need for federal oversight". Hastings Law Journal, núm. 64, 2013, pp.499-527.

- BUTLER, J. M., Forensic DNA Typing, Elsevier Academic Press, Burlington (MA), USA, 2005.

- CALE, C. M., EARLL, M., LATHAM, K. E., BUSH, G. L., "Could secondary DNA transfer falsely place someone at the scene of a crime?”, J. Forensic Sci., vol. 61, 2016, pp. 196-203.

- CALE, C. M., "Forensic DNA evidence is not infallible”, Nature, vol. 526, 2015, pp. 611.

- CAllaghAN, T. F., "Responsible genetic genealogy”, Science, vol. 366, 2019, pp. 155.

- CALlAWAY, E., "Privacy concerns over DNA used for crime investigation", Science, vol. 562, 2018, pp. 315-316.

- CENTRO TECNOLÓGICO DE SEGURIDAD, Base de datos policial de identificadores obtenidos a partir de ADN, Ministerio del Interior, Secretaría de Estado de Seguridad, Madrid, 2019.

- COMISIÓN NACIONAL PARA EL USO FORENSE DEL ADN. Actividades 2009-2012, Ministerio de Justicia, Secretaría General Técnica, Madrid, 2011.

- ERLICH, Y., SHOR, T., PE'ER, I., CARMI, S., "Identity inference of genomic data using long-range familial searches", Science, vol. 362, 2018, pp. 690-694.

- ESMAILI, S., "Searching for a needle in a haystack: the constitutionally of police DNA dragnets", Chicago-Kent Law Review, vol. 82, 2007, pp. 495-523.

- GARCÍA, O., CRESPILLO, M., YURREBASO, I., "Suspects identification through 'familial searching' in DNA databases of criminal interest. Social, ethical and scientific implications", Rev. Esp. Med. Legal, vol. 43, 2017, pp. 26-34.

- GILL, P., "DNA evidence and miscarriages of justice”, Forensic Sci. Intern., vol. 294, 2019, pp. e1-e3.

- GOODWIN, W., LINACRE, A., HADI, S., An introduction to Forensic Genetics, John Wiley and Sons, Ltd. Chichester, UK, 2007.

https://plato.stanford.edu/entries/value-theory/ (consultada el 2 de noviembre 2021) y https://plato.stanford.edu/entries/fitting-attitude-theories/ (consultada el 2 de noviembre 2021) 
- GREYTAK, E.M., MOORE, C., ARMENTROUT, S.L., "Genetic genealogy for cold case and active investigations", Forensic Science International, vol. 299, 2019, pp. 103-113.

- HARTMANN, N., Ética, Ediciones Encuentro S.A., Madrid, 2011.

- HAZEL, J.W., CLAYTON, E.W., MALIN, B.A., SLOBOGIN, C., "Is it time for a universal genetic forensic database?", Science, vol. 362, 2018, pp. 898-900.

- HOUCK, M.M., SIEGEL, J.A., Fundamentals of Forensic Science. Elsevier Academic Press, Burlington (MA), USA, 2006.

- JEFFREYS, A.J., "Genetic fingerprinting”, Nature Medicine, vol. 11, 2005, pp. 1035-1039.

- JOBLING, M.A., GILL, P., "Encoded evidence: DNA in forensic analysis", Nat. Rev. Genet., vol. 5, 2004, pp. 739-751.

- JOLY, Y., MARROCCO, G., DUPRAS, C., "Risks of compulsory genetic databases", Science, vol. 363, 2019, pp. 938.

- KAYE, D.H., The double helix and the law of evidence, Harvard University Press, Cambridge (MA), USA, 2010.

- $\quad$ KIM, J., EDGE, M.D., ALGEE-HEWITT, B.F.D., LI, J.Z., ROSENBERG, N.A., "Statistical detection of relatives typed with disjoint forensic and biomedical loci", Cell, vol. 175, 2018, pp. 848-858.

- KRIMSKY, S., SIMONCELLI, T., Genetic Justice, Columbia University Press, N.Y., 2011.

- MARFANY, G., “¿Quién quiere tu ADN?”, Mètode U.V., vol. 104, 2020, pp. 99.

- MESTRES, F., ZIVANOVIC, G., "Some applications of DNA databanks as an investigative tool for solving criminal cases", J. Criminal. and Law, vol. 23, 2018, pp. 233-250.

- MESTRES, F., "La utilización del concepto de ADN en nuestra sociedad: tecnociencia, frases hechas y errores científicos", Sociol. Tecnol., vol. 2, 2012, pp. 33-43.

- MESTRES, F., VIVES-REGO, J., "Identificación de características forenses avanzadas a partir del ADN: etnogeografía, patología delictiva y morfoanatomía”, La Ley Penal, núm. 91, 2012, pp. 48-56.

- MESTRES, F., VIVES-REGO, J., "Genética forense: entre la tecnociencia y la imaginación”, Ludus Vitalis, vol. 17, 2009a, pp. 447-450.

- MESTRES, F., VIVES-REGO, J., "Bancos y bases de datos genéticos para usos forenses", Rev. Poder Judicial, núm. 89, 2009b, pp. 239-263.

- MILLER, G., "Familial DNA testing scores a win in serial killer case", Science, vol. 329, 2010, pp. 262.

- MONTES, F. "El ADN en la investigación criminal", Boletín del Instituto Universitario de Investigación sobre Seguridad Interior, 2005, pp. 1-10.

- NIEMIEC, E., HOWARD, H. C., "Ethical issues in consumer genome sequencing: Use of consumers' samples and data", Appl. Transl. Genom., vol. 8, 2016, pp. 23-30.

- RAM, N., GUERRINI, C.J., MCGUIRE, A.L., "Genealogy databases and the future of criminal investigation”, Science, vol. 360, 2018, pp. 1078-1079.

- SCUDDER, N., MCNEVIN, D., KELTY, S.F., FUNK, C., WALSH, S. J., ROBERTSON, J., "Policy and regulatory implications of the new frontier of forensic genomics: direct-to- 
consumer genetic data and genealogy records", Curr. Issues Crim. Justice, vol 31, 2019, pp.194-216.

- VIVES-REGO, J., "Environmental Forensics: a scientific service at the service of Justice and Society". Environ. Forensics, vol. 5, 2004, pp.123-124.

- WALKer, S., "Police DNA 'sweeps' extremely unproductive", Dept. Criminal Justice, University of Nebraska at Omaha, 2004.

- WALlACE, H.M., JACKSON, A.R., GRUBER, J., THIBEDEAU, A.D., "Forensic DNA databases-Ethical and legal standards: A global review", Egypt. J. Forensic Sci., vol. 4, 2014, pp. 57-63.

- WALSH, S.J., CURRAN, J.M., BUCKLETON, J.S., "Modeling forensic DNA database performance", J. Forensic Sci., vol. 55, 2010, pp. 1174-1183. 